\title{
Comparative Study of 35 HP Range Tractors
}

\author{
T.K. Maheshwari ${ }^{1}$, Devesh Kumar $^{2 *}$ and Manish Kumar ${ }^{2}$ \\ ${ }^{1}$ Dr. B.R.A College of Agricultural Engineering \& Technology Etawah U.P., India \\ ${ }^{2}$ Department of Farm Machinery and Power Engineering SHUATs Allahabad, U.P., India \\ *Corresponding author
}

\begin{abstract}
A B S T R A C T
Agriculture is the most important sector of Indian economy. About $78 \%$ farm holdings belong to small and marginal farmers, about $22 \%$ belongs to semi medium, medium and large farm holders. Therefore, $35 \mathrm{hp}$ tractors are most commonly used in India. Torque of

Keywords

Tractor, Torque, Horsepower and Speed.

\section{Article Info}

Accepted:

17 September 2017

Available Online:

10 October 2017

Swaraj tractor is best in the comparison of other tractor manufacturers which is $14 \mathrm{~kg}-\mathrm{m}$ at the standard speed. Engine speed of Mahindra and Mahindra tractor found greater than the other tractor manufacturers. It is found $2300 \mathrm{rpm}$. Displacement volume of Swaraj tractor is $2600 \mathrm{cc}$ which is greater than other tractors. Escorts and Swaraj tractors have upto speed $1000 \mathrm{rpm}$ which is greater than the other tractors. HMT, New Holland and Sonalika tractors have more hydraulic lifting capacity as the compare of other tractors. $1200 \mathrm{~kg}$ weight can lift by these tractors. PTO power of Swaraj and HMT is the best as the comparison of other tractor manufacturers. It is found $34 \mathrm{hp}$ in these tractors. Mean effective pressure of cylinder of TAFE tractor is $6.85 \mathrm{~kg} / \mathrm{cm}^{2}$ which is greater than the other tractor manufacturers. Swaraj tractor has the minimum noise level which is comfortable or operator and the value of noise level for this tractor is $90 \mathrm{db}$. From the above points, it was concluded on the basis of specific fuel consumption which was minimum among different tractors i.e. $0.2 \mathrm{~kg} / \mathrm{kWh}$ to $0.25 \mathrm{~kg} / \mathrm{kWh}$ at the torque $10.9 \mathrm{~kg}-\mathrm{m}$ for Mahindra tractor. But for maximum torque i.e. $13.5 \mathrm{~kg}-\mathrm{m}$ at the rated speed of 1400 rpm of Swaraj tractor.
\end{abstract}

\section{Introduction}

Agriculture is the most important sector of Indian economy. Most of the farming is done on small holding. About $78 \%$ farm holdings belong to small and marginal farmers, about $22 \%$ belongs to semi medium, medium and large farm holders Therefore, $35 \mathrm{hp}$ tractors are most commonly used in India. Tractor is a main source of power on the farm. The main reason of using $35 \mathrm{hp}$ tractors in India is that a large strength of farmers is belonging to poor and small land holdings. Market growth is about $4-5 \%$ per annum. Government Subsidy drives sales but there is no subsidy on tractors above $35 \mathrm{hp}$. Domestic sectors growing due to an increase in the irrigated area, Government policy related to export which decides crop switching by farmers. Smaller tractors are very popular (35 hp); this is the fastest growing segment. Tractor is a self-propelled power unit having wheels or tracks for operating agricultural implements and machines including trailers. It gets its driving force in the combination with an engine and driving wheels or tracks. 


\section{Materials and Methods}

\section{Escort}

\section{Engine}

The $35 \mathrm{hp}$ escort tractor has engine of 3 no. of cylinder, the bore and stroke is $91 \mathrm{~mm}$ and 110 $\mathrm{mm}$, respectively. The displacement volume of piston is $2146 \mathrm{cc}$, compression ratio is 18:1, the maximum torque is $13.2 \mathrm{~kg}-\mathrm{m}$; the rated engine rpm of the engine is $2200 \mathrm{rpm}$.

\section{Transmission system}

The constant mesh type gear box is used, the 8 forward and 2 reverse with high-low selector lever is present in this system. The single plate type cultch of $250 \mathrm{~mm}$ is present in this tractor. The single sped PTO is fitted, the dia. and no. of spline is $34.67 \mathrm{~mm}$ and 21respectively. The rpm of PTO is 1000 at the engine rpm 1863. The maximum PTO hp is $31 \mathrm{hp}$.

\section{Brake}

The disc brake is present in this tractor. The brake pedal is with $38-43 \mathrm{~mm}$.

\section{Hydraulic system}

The automatic draft and position control hydraulic system is fitted in this tractor, the lifting capacity of systemic $1000 \mathrm{~kg}$ at end of lower links. The gear type pump is used.

\section{HMT}

\section{Engine}

The HMT Tractor has a $40 \mathrm{hp} \mathrm{HMT} \mathrm{AVL}$ engine, this engine is four stroke water cooled engine. The bore and stroke of the engine is $95 \mathrm{~mm}$ and $110 \mathrm{~mm}$ respectively, displacement volume is $2340 \mathrm{cc}$, the compression ratio is $17.4: 1$ and the rated rpm is 2100 .

\section{Transmission}

The dual clutch is fitted in this tractor, the two dry plates with the diameter $295 \mathrm{~mm}$ and thickness of $9.5 \mathrm{~mm}$, one plate for tractor drive and the other for PTO shaft drive. 8 forward and 2 reverse speeds with high low selector are available.

PTO Independent standard rpm 545 at 2100 engine rpm. Ground PTO rpm 271 to 1150 rpm available through gearbox at rated engine rpm.

\section{Brakes}

The brake levers are available foot brake and hand brake. Mechanical disc brake, operated by two pedals with latch to brake the wheels simultaneously and independently. The hand brake is Integral with pedal which is locked by latch.

\section{Mahindra \& Mahindra}

\section{Engine}

The Mahindra $35 \mathrm{hp}$ tractor has engine type MDI 1785, the no. of cylinder in this engine is three, the bore and stroke is $88.9 \mathrm{~mm}$ and $96 \mathrm{~mm}$ respectively, the displacement is 1788 cc, and rated rpm of engine is 2300 .

\section{Transmission system}

The sliding mesh gear box having 8 forward and 2 reverse speeds with high- low selector lever, the cultch having 10" single dry driven plate in fitted and the rear mounted PTO having six splines and $627 \mathrm{rpm}$ (low range) at rated engine rpm.

\section{Brakes}

Totally enclosed, self-energizing, disc with dry friction liner type brakes is used in this tractor. 


\section{Hydraulic system}

Vary tough, fully live hydraulic with position and draft control hydraulic system is fitted in this tractor, the lifting capacity is $100 \mathrm{kgf}$ at the end of lower links.

\section{Electrical system}

The electric system of this tractor is consist of 12-volt battery, solenoid operated starter motor, generator, regulator, head light, rear brake light, parking lights, turning light, plough lamp, fuse box registration lamp, horn etc.

\section{TAFE}

\section{Engine}

Diesel engine in tractor has 3 cylinders and bore stroke ratio is 0.7 . The cubic capacity (cc) is 2365 , rated rpm 2000.

\section{Transmission}

The clutch has oil bath type and single. The transmission 6 forward and 2 reverse gear, the max speed on the road $26.18 \mathrm{~km} / \mathrm{h}$, max forward speed $13.31 \mathrm{kmph}$ and reverse speed 6 $\mathrm{km} / \mathrm{h}$. the pto has $540 \mathrm{rpm} @ 1500$ ERPM and no. of splines is make1, speed of operation is position draft, response controls

\section{Hydraulic system}

The hydraulic system is 1100 (lower link in horizontal position), the lifting capacity has $1100 \mathrm{~kg}$

\section{Swaraj}

\section{Engine}

Swaraj tractor has $39 \mathrm{hp}$ range and model is $\mathrm{R}$ V-3 T.R; Kirlosker. This tractor has four stroke, direct ignition diesel engine. Number of cylinders in this engine are 3 and bore stroke is $100 \times 110 \mathrm{~mm}$. Rated speed of engine is 2000 revaluation/min and displacement of piston is $2592 \mathrm{cc}$.

\section{Transmission system}

Transmission system of this tractor has a heavy duty, single dry plate type clutch of 280 $\mathrm{mm}$ diameter. Number of gears is $8+2$ (by high and low selector lever). Maximum speed of tractor is $28 \mathrm{~km} / \mathrm{hr}$ in forward direction and $12 \mathrm{~km} / \mathrm{hr}$ in reverse direction. PTO of 21 splines have $1000 \mathrm{rpm}$ at rated engine speed. A shaft of 6 splines can also be used which have $540 \mathrm{rpm}$ with an engine speed of 1650 rpm.

\section{Brakes}

High working capacity, self-energizing, water proof disc brakes are used in this tractor. Oil immersed multi disc brake can also be used in this tractor.

\section{Hydraulic system}

A two-lever live hydraulic system-automatic position with draft and mix control is provided in this tractor. A gear type hydraulic lift pump is used in this system for the purpose of oil transfer with a speed of 17 liter/min at rated engine speed.

\section{SONALIKA}

\section{Engine}

The 35 hpsonalika tractor has contain 3 cylinder, direct injection cooled diesel engine and its bore stroke ratio $95 / 118$ in this tractor compression ratio is 18:4:1 and its displacement 2510, rated rpm 2100,max torque $(\mathrm{Nm}) 140, \mathrm{sfc}$ at rate speed has $184 \mathrm{gm}$ /ps.hr. 


\section{Transmission}

The constant mesh type gear box with high low selector lever is present in this tractor In this tractor is single dry type plates the dia of plate is $280 \mathrm{~mm}$ the single speed live pto is used in this tractor, the no of spline and rpm of pto is 6 and 540 respectively speed the maximum pto power $30.57 \mathrm{hp}$.

\section{Brake}

In this tractor have dry disc brake /oil immersed brakes.

\section{Hydraulic}

In this tractor has constant 2 levers, automatic position \& Draft, lifting capacity $(\mathrm{kg})$ is 1200 .

\section{Results and Discussion}

The laboratory test on testing centre and the field operation on $35 \mathrm{hp}$ tractors is give the following main aspect on which the comparison of different manufacturer's tractors is performed. The following are the main aspect on which the comparison takes place:

\section{Torque and engine speed}

Like power, toque is an important measure of engine performance. Any force applied on some point to cause a turning effect is called torque, mathematically represented by force multiplied by the distance of force from the centre of shaft, i.e. Torque,

$\mathrm{T}=\mathrm{F} \times \mathrm{r}$

As shown in graph 1 the hp curve continuous to rise as the engine speed increase until maximum power is attained. This is also true with the torque curve, but the torque will reach its maximum point much earlier. An engine develops more toques at intermediate speeds than at the maximum speed. This is because the volumetric efficiency is higher at intermediate speeds.

\section{Torque}

The maximum torque is obtained at a standard engine speed of $1400 \mathrm{rpm}$. The different tractor manufacturer like, Swaraj, TAFE, Mahindra, Escorts, HMT, New Holland, Sonalika is specified the values of torque is 13.97 kg-m, $12.90 \mathrm{~kg}-\mathrm{m}, 10.90 \mathrm{~kg}-\mathrm{m}, 13.46$ kg-m, $13.65 \mathrm{~kg}-\mathrm{m}, 11.94 \mathrm{~kg}-\mathrm{m}$ and $11.94 \mathrm{~kg}-$ $\mathrm{m}$ respectively. These values of torque are plotted against engine rpm at a rated speed of $1800 \mathrm{rpm}$. Swaraj tractor is best because torque of this is maximum in 35 H.P. series tractors. The comparison of torque is given in graph 2.

\section{Engine speed}

Tractors are mostly equipped with high speed engines running at about $2000 \mathrm{rpm}$. The different tractor manufacturers like Swaraj, TAFE, Mahindra, Escorts, HMT, New Holland, Sonalika are provide the engine rpm 1800, 2000, 2300, 2000, 2100, 2100 and 2100 respectively. The comparison of engine rpm is shown in graph 3.

\section{Displacement volume}

The displacement volume is specified by different tractor manufacturer like Swaraj, TAFE, Mahindra, Escorts, HMT, New Holland and Sonalika are $2592 \mathrm{cc}, 2400 \mathrm{cc}$, 2788 cc, 2146 cc, 2340 cc, 2500 cc, and 2510 cc respectively. The comparison of displacement volume of different tractors is shown in graph 4.

\section{Number of gear}

Gear box is fitted between the engine and rear wheel for variable torque and speed. The different tractor manufacturer specified different numbers of gears. Such as Swaraj, 
TAFE, Mahindra, Escorts, HMT, New Holland and Sonalika have the no. of gears six forward and two reverse, six forward and two reverse, eight forward and two reverse, eight forward and two reverse, eight forward and two reverse, eight forward and two reverse, and eight forward and two reverse respectively. It is shown in graph 5.

\section{PTO speed}

The PTO shaft is an extension of the gearbox lay shaft which is being continuously driven. Both of these shafts rotate in clockwise direction when viewed from the rear of the tractor. The PTO speed of different tractor such as Swaraj, TAFE, Mahindra, escorts, HMT, New Holland and sonalika are 1000, 540, 623, 1000, 540, $540 \& 540$ respectively. The comparison is shown in graph 6 .

\section{Stroke-bore ratio}

It is the ratio of length of piston stroke to diameter of the cylinder. This ratio for the tractor engine is about 1.25 and it varies between 1-1.45. The stroke-bore ratio of different tractor manufacturer like Swaraj, TAFE, Mahindra, Escorts, HMT, New Holland, and Sonalika recommended 1.1, $1.4285,1.07986,1.20879,1.1578,1.00$ and 1.242 respectively. The difference of strokebore ratio is drawn in the graph 7 .

\section{Discharge of hydraulic pump}

The volume of oil delivered by pump per minutes is called discharge capacity of hydraulic pump; the time taking in raising or lowering the lift is depends upon discharge of pump. The discharge of different tractor manufacturers is recommended such as Swaraj, TAFE, Mahindra, escorts, HMT, New Holland and sonalika are 17, 16, 9.5, 22, 22, $18 \& 17.5$ liters per minute respectively. The comparison is shown in graph 8.

\section{Lifting capacity of hydraulic system}

The lifting capacity of different manufacturers of $35 \mathrm{hp}$ tractors such as, Swaraj, TAFE, Mahindra, Escorts, HMT, New Holland and Sonalika are 1000, 1100, 1000, 1000, 1200, 1200 and $1200 \mathrm{~kg}$ respectively. The comparison of lifting capacity is shown in graph 9. The tractor used in such type of work should have maximum lifting capacity in 35 H.P. series H.M.T., New Holland and sonalika is best with lifting capacity of each tractor $1200 \mathrm{~kg}$.

\section{Minimum speed of the tractors}

The minimum speed of a tractor is obtained in first-low gear; in this gear the maximum torque is obtained. Minimum speed of different tractors is expressed in $\mathrm{km} / \mathrm{h}$.

The recommended minimum speed of Swaraj, TAFE, Mahindra, Escorts, HMT, New Holland and Sonalika is 2.23, 2.23, 2.1, 2.06, 2.1, 2.50 and $2.65 \mathrm{~km} / \mathrm{h}$ respectively. These values of minimum speed of tractors are drawn in the graph 10. At the minimum speed of tractor, the maximum torque is obtained.

\section{Maximum speed of the tractors}

The maximum speed of a tractor is obtained in top-high gear; in this gear the minimum torque is obtained. Maximum speed of different tractors is expressed in $\mathrm{km} / \mathrm{h}$. The recommended maximum speed of Swaraj, TAFE, Mahindra, Escorts, HMT, New Holland and Sonalika is 27.4, 22.24, 26.90 26.88, 30.00, 28.04 and $30.00 \mathrm{~km} / \mathrm{h}$ respectively. It is shown in graph 11 .

\section{Maximum PTO power}

The PTO is least used and most efficient power outlet of tractors. The maximum power of pto shaft of different tractors such as, Swaraj, TAFE, Mahindra, escorts, HMT, new 
Holland and sonalika are 34, 30, 30.57, 31, 34, 30.8and 30.57 respectively. The comparison of pto hp. is shown in graph 12 .

\section{Mean effective pressure}

This pressure actually forces the piston down during the power stroke. The mean effective

Graph.1 RPM VS Horsepower at a Standard Speed 1400 Rpm.

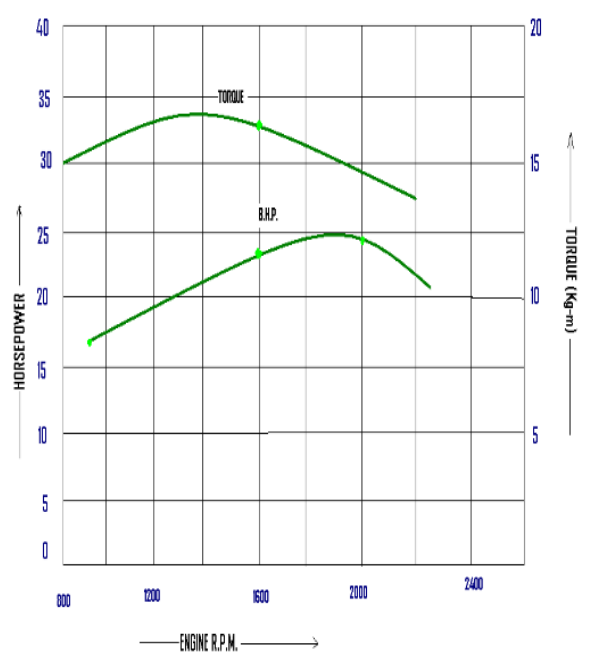

Graph.3 Comparison of Engine Speed of Tractors

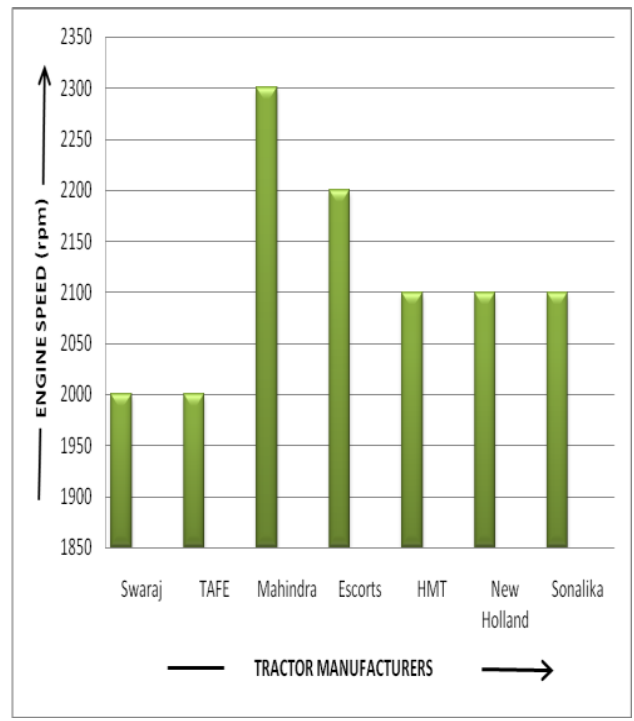

pressure for different tractor manufacturers like Swaraj, TAFE, Mahindra, Escorts, HMT, New Holland, Sonalika are 6.774, 6.853, 6.40, $6.674,6.599, \quad 6.45$ and $5.98 \mathrm{~kg} / \mathrm{cm}^{2}$ respectively.

The comparison of mean effective pressure is shown in graph 13.

Graph.2 Comparison of Maximum Torque

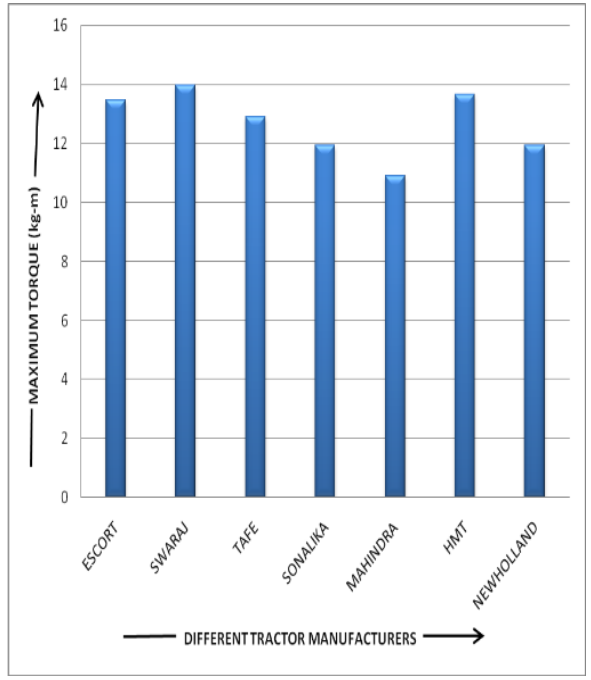

Graph.4 Comparison of Displacement Volume

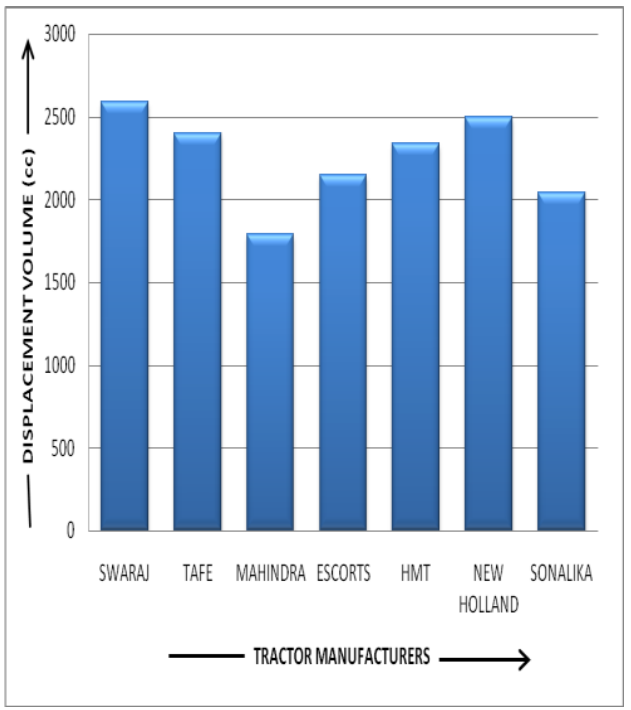


Graph.5 Comparison of no. of gears of tractors

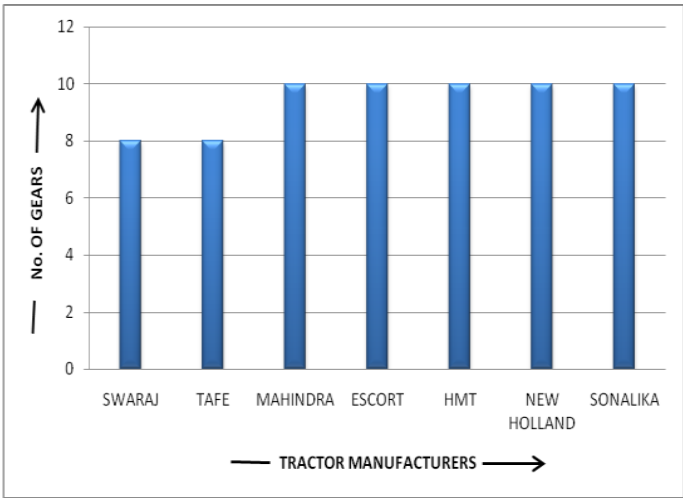

Graph.7 Comparison of Stroke /Bore Ratio of Tractors Cylinder

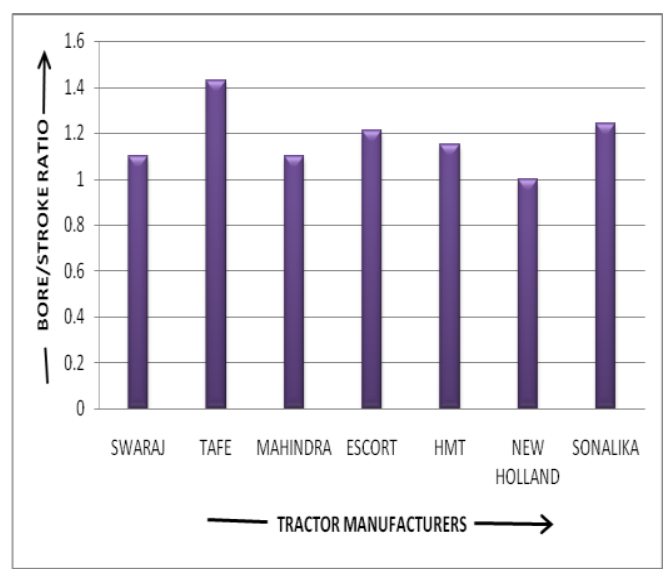

Graph.9 Comparison of Lifting Capacity of Hydraulic Lift of Tractors

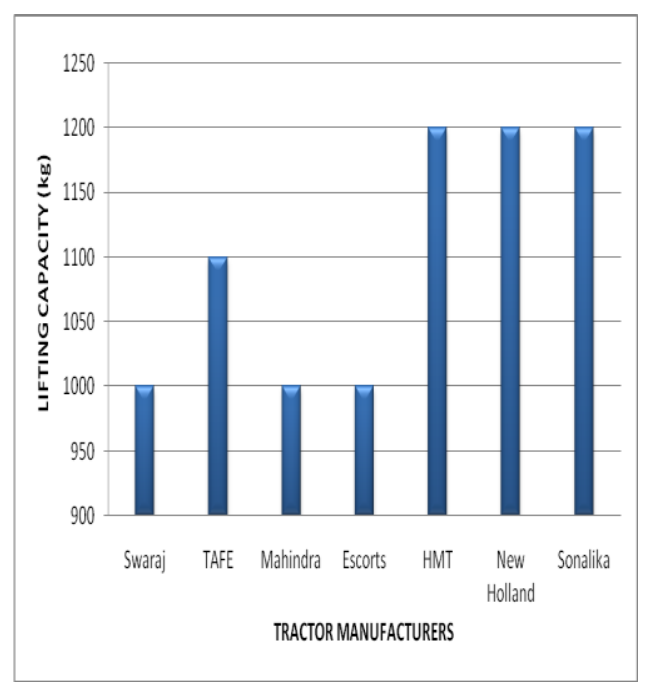

Graph.6 Comparison of PTO Speed of different Tractors

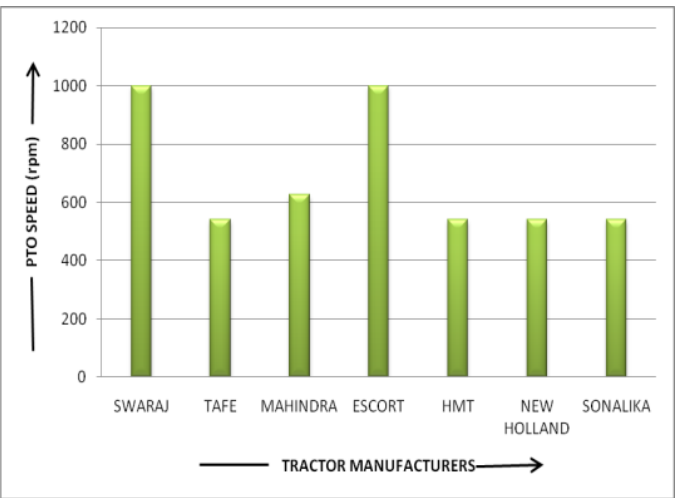

Graph.8 Discharge of Hydraulic Pump of Tracctors

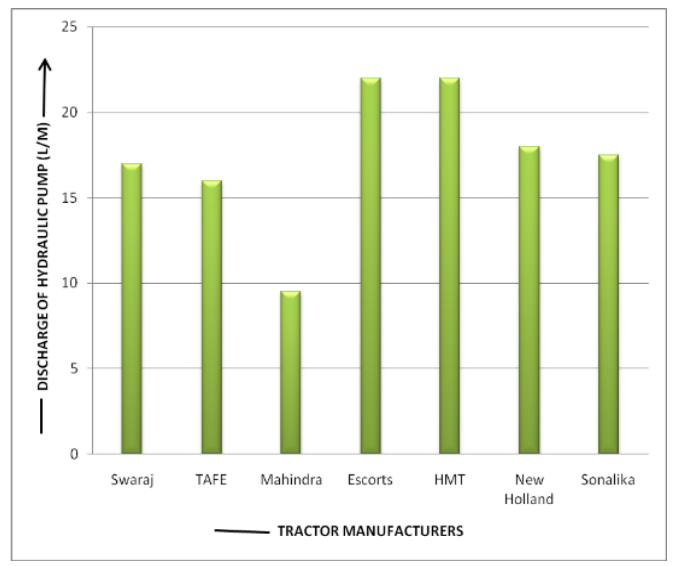

Graph.10 Minimum Speed of Tractors

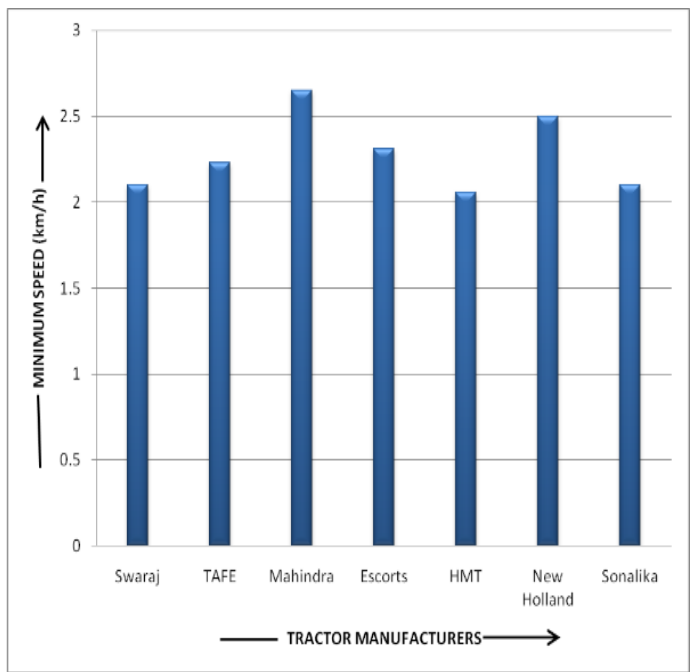


Graph.11 Maximum Speed of Tractors.

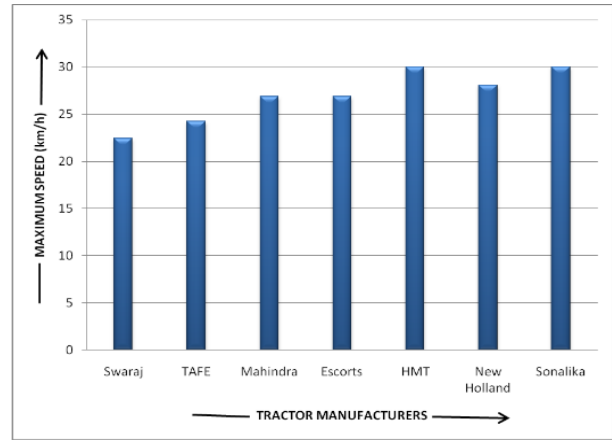

Graph.13 Mean Effective Pressure of Cylinder

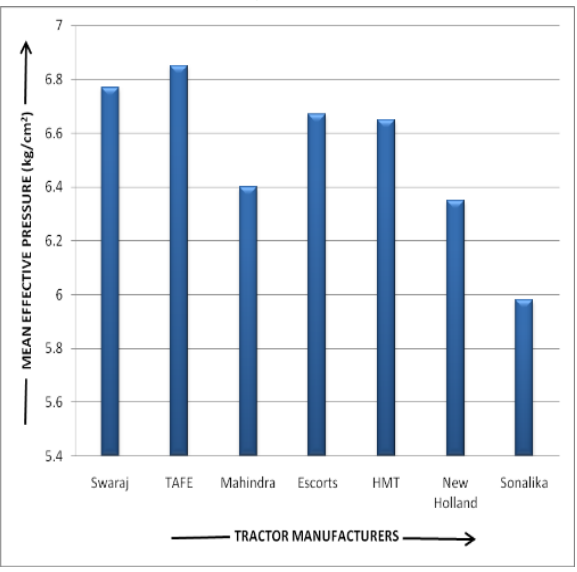

Graph.15 Fuel Injection Pressure of Injection of Different Tractor Engines Tractors.

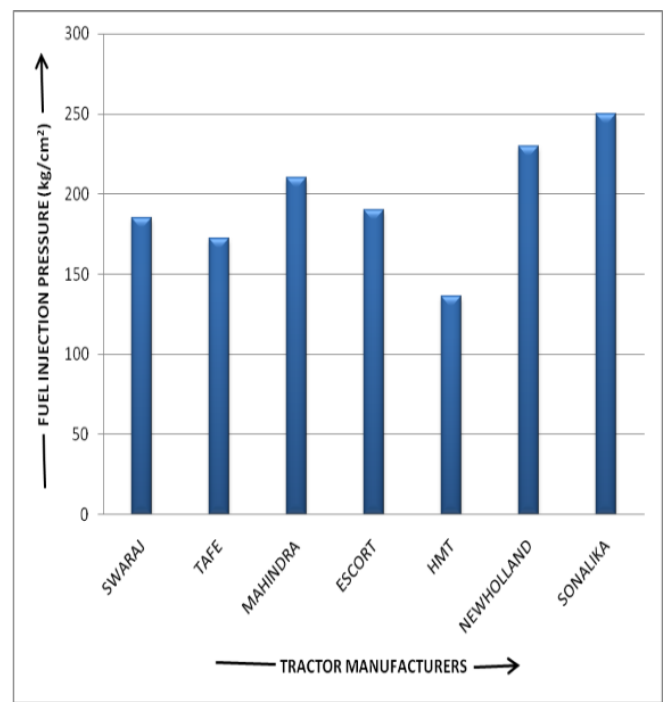

Graph.12 Comparison of Maximum PTO Power of different Tractors

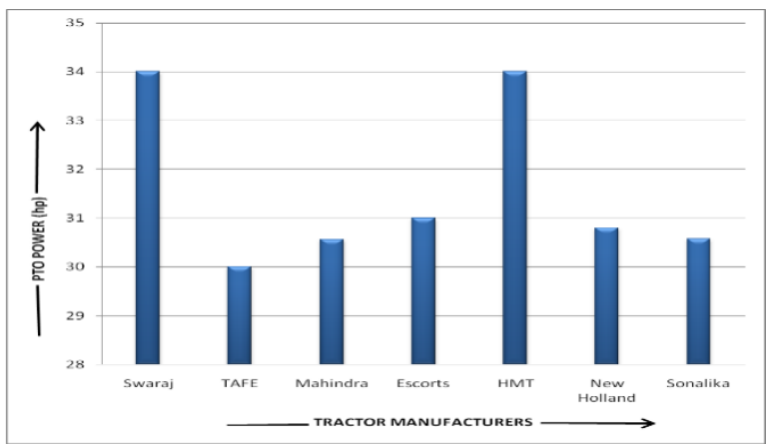

Graph.14 Total Weight of different Tractors

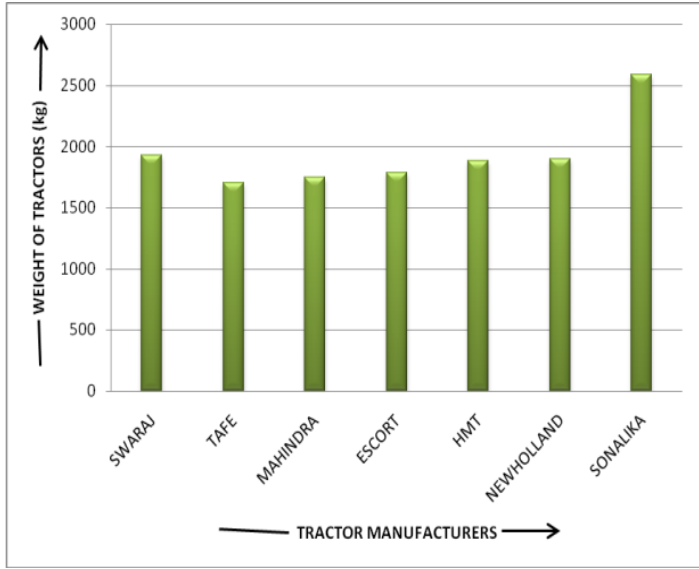

Graph.16 Governed Range of Engine Speed of Pump

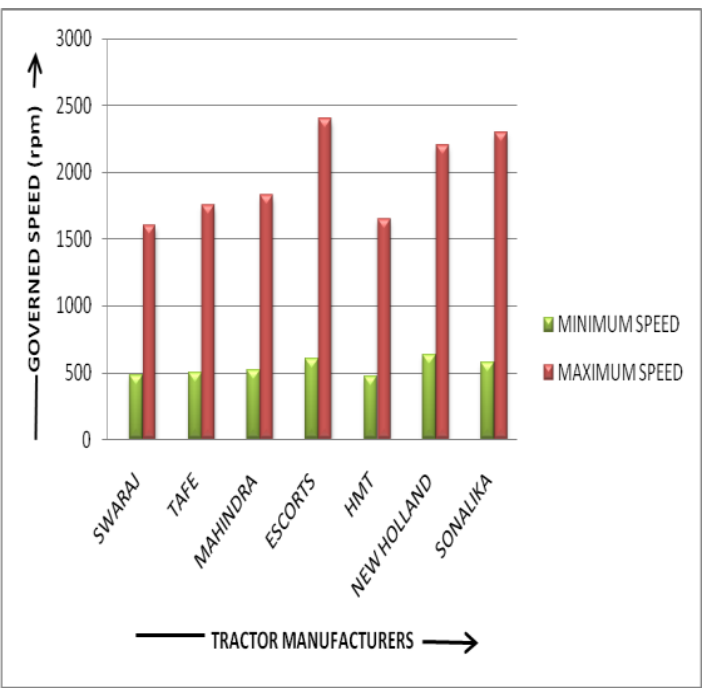




\section{Graph.17 Comparison of Noise Level of Different Tractors}

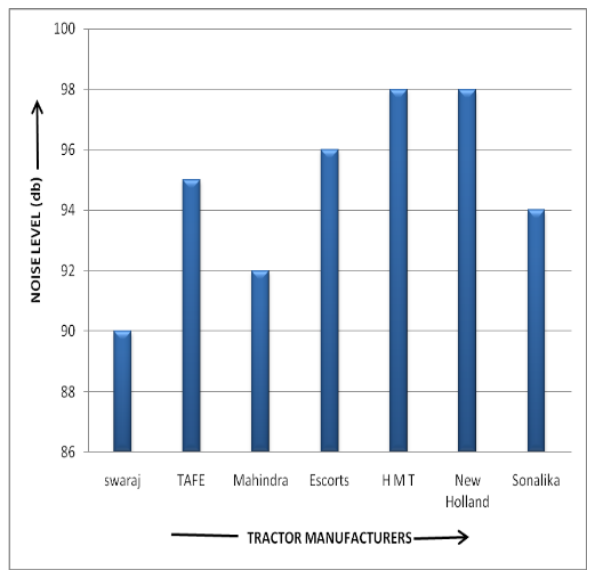

\section{Weight of tractor}

The tractors have a range of weight approximately $1700-2600 \quad \mathrm{~kg}$. The recommended weight of different tractor manufacturer like Swaraj, TAFE, Mahindra, Escorts, HMT, New Holland and Sonalika is $1925 \mathrm{~kg}, 1700 \mathrm{~kg}, 1745 \mathrm{~kg}, 1785 \mathrm{~kg}, 1880 \mathrm{~kg}$, $1900 \mathrm{~kg}$ and $2590 \mathrm{~kg}$ respectively. The graph based on the weight of tractors is drawn in the graph 14.

\section{Fuel injection pressure}

The fuel is injected with very high pressure, it is known as fuel injection pressure. It is always higher then comprised air, this pressure is varies from 125 to $250 \mathrm{~kg} / \mathrm{cm}^{2}$. The injection pressure for different tractors such as, Swaraj, TAFE, Mahindra, Escorts, HMT, New Holland and Sonalika are 185, 172, 210, 190, 136, 230 and 250 respectively. The comparison is shown in graph 15 .

\section{Governed engine speed}

Variation of the governed engine speed of different tractors such as Swaraj, TAFE, Mahindra, Escorts, HMT, New Holland and Sonalika are 480-2300, 510-2100, 520-2600, 600-2900, 450-200, 700-2700 and 695-2550
Graph.18 Comparison of Exhaust Gas pressure

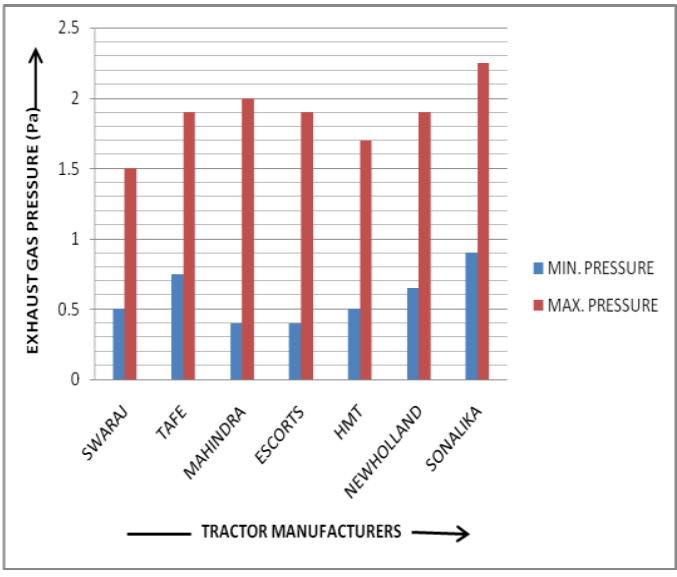

rpm respectively. The corresponding governed engine speed of each tractor shown in the graph 16.

\section{Noise level}

The noise level of different tractors such as Swaraj, TAFE, Mahindra, Escorts, HMT, New Holland and Sonalika are 90, 95, 92, 96, 98, 98, and $94 \mathrm{db}$ respectively. The noise level of tractor is effect the working efficiency of operator. The noise level of tractor should be minimum as possible as, the minimum noise level in $35 \mathrm{hp}$ tractors is in Swaraj in the range of $90 \mathrm{db}$. Is is shown in graph 17.

\section{Exhaust gas pressure}

Different tractor manufacturer recommended different exhaust pressure for the tractors. Some manufacturers such as Swaraj, TAFE, Mahindra, Escorts, HMT, New Holland and Sonalika recommended the exhaust pressure range $0.5-1.5,0.8-1.9,0.4-2,0.4-1.87,0.5-$ $1.7,0.65-1.93$ and $0.95-2.2 \mathrm{kPa}$ respectively. The difference of exhaust pressure is drawn in the graph 18 .

The technical specification data of $35 \mathrm{hp}$ tractors was collected from different tractor 
industry and different tractor testing centers. There are following conclusion could be drawn:

Torque of Swaraj tractor is best in the comparison of other tractor manufacturers which is $14 \mathrm{~kg}-\mathrm{m}$ at the standard speed.

Engine speed of Mahindra \& Mahindra tractor found greater than the other tractor manufacturers. It is found $2300 \mathrm{rpm}$.

Displacement volume of Swaraj tractor is $2600 \mathrm{cc}$ which is greater than other tractors.

There are 10 gears found in five tractors out of seven. Those tractors are Mahindra \& Mahindra, Escorts, HMT, New Holland and Sonalika.

Escorts and Swaraj tractors have PTO speed $1000 \mathrm{rpm}$ which is greater than the other tractors.

HMT, New Holland and Sonalika tractors have more hydraulic lifting capacity as the compare of other tractors. $1200 \mathrm{~kg}$ weight can lift by these tractors.

PTO power of Swaraj and HMT is the best as the comparison of other tractor manufacturers. It is found $34 \mathrm{hp}$ in these tractors.

Mean effective pressure of cylinder of TAFE tractor is $6.85 \mathrm{~kg} / \mathrm{cm}^{2}$ which is greater than the other tractor manufacturers.

Swaraj tractor has the minimum noise level which is comfortable or operator and the value of noise level for this tractor is $90 \mathrm{db}$.

Specific fuel consumption of Mahindra \& Mahindra tractor is lesser than the other tractor manufacturers. From the above points, it was concluded on the basis of specific fuel consumption which was minimum among different tractors i.e. $0.2 \mathrm{~kg} / \mathrm{kWh}$ to 0.25 $\mathrm{kg} / \mathrm{kWh}$ at the torque $10.9 \mathrm{~kg}-\mathrm{m}$ for Mahindra tractor. But for maximum torque i.e. $13.5 \mathrm{~kg}$ $\mathrm{m}$ at the rated speed of $1400 \mathrm{rpm}$ of Swaraj tractor. So it was concluded that for heavy work load Swaraj tractor is best but on the basis of specific fuel consumption Mahindra tractor is best.

\section{References}

Heywood, J.B., 1988. Internal Combustion Engine Fundamentals. New York, USA: McGraw-Hill.

Jagdishwar Sahay, 2004. Elements of Agricultural Engineering, Fourth Edition, Standard Publishers Distributer, July, 2004.

Jain S.C., and C.R. Rai 1999. Farm Tractor Maintenance and Repair, Second Revised \& Enlarged Edition, Budni.

Jones, F.R., 1957. Farm Gas Engines and Tractors, McGraw Hill Book Company, Inc., New York.

Klenin, N.I., \& Others 1985. Agricultural Machines: Theory of Operation. Computation of Controlling Parameters and the Conditions of Operation. Amerind Publishing Co. Pvt. Ltd. New Delhi.

Liljedhal, John, B., Turnquist, Paul K. and Smith David W. 1999. Tractor and Their Power Units. CBS Publishers and Distributers, New Delhi.

Mallika Srinivasan, TAFE. 2000-2001. Central Statistical Organisation, the Indian economy grew at only 4 per cent in 2000-2001, agriculture saw a negative growth of -0.4 per cent. The tractor manufacturing company of the Amalgamations Group,

Moses, B.D., and K.R. Frost 1952. Farm Power, John Wiley \& Sons, Inc., New York, 1952.

Nakra, C.P., 2006. Farm Machines and 
Equipment, Dhanpat Rai Publishing Company (P) Ltd. New Delhi.

Ojha T.P., and A. M. Micheal 2006. Principles of Agricultural Engineering, Sixth Edition, Vol.-I, Jain Brothers Publishers, New Delhi.

Parimal, P.S., Doyle E.F. 1976 Feb. Compounding the truck diesel engine with an organic Rankine cycle system.

Schumacher, Leon G., et al., 1996. "Heavyduty Engine Exhaust Emission Tests Using Methyl Ester Soybean Oil/Diesel Fuel Blends," Bioresource Technology,
Volume 57, Issue.

Service Manuals. Service manual of Swaraj, TAFE, Mahindra, Escorts, HMT, New Holland, and Sonalika Tractors.

Sethl, V.P., and Salariya, K.S. 2004. Exhaust analysis and performance of a single cylinder diesel engine run a dual fuels. I.E (1) Journal - MC. Vol. 85 Pp. 3-5.

Suresh, R., 2003. Farm Power and Machinery Engineering, First Edition, Standard Publishers Distributers, New Delhi, 2003.

\section{How to cite this article:}

Maheshwari, T.K., Devesh Kumar and Manish Kumar. 2017. Comparative Study of 35 HP Range Tractors. Int.J.Curr.Microbiol.App.Sci. 6(10): 1890-1900. doi: https://doi.org/10.20546/ijcmas.2017.610.228 